\title{
CDISC SDTM Cardiac Valvular Stenosis Severity Terminology
}

National Cancer Institute

\section{Source}

National Cancer Institute. CDISC SDTM Cardiac Valvular Stenosis Severity Terminology. NCI Thesaurus. Code C101854.

Terminology associated with the cardiac valvular stenosis severity codelist of the Clinical Data Interchange Standards Consortium (CDISC) Study Data Tabulation Model (SDT M). 